\title{
Open Government Partnership na cidade de São Paulo e o programa São Paulo Aberta: desafios na difusão e institucionalização de uma política global
}

\author{
GABRIELA DE BRELÀZ ${ }^{1}$ \\ TAMARA ILINSKY CRANTSCHANINOV ${ }^{2}$ \\ LAILA BELLIX ${ }^{3}$ \\ ${ }^{1}$ Universidade federal de São Paulo (UnifeSP) / Escola Paulista de Política, Economia e Negócios, Osasco - SP, Brasil \\ ${ }^{2}$ Fundação Escola de Sociologia e Política de SÃo Paulo (FESPSP) / Programa de Pós-Graduação em CiênCIA Política, \\ SÃO PAULO - SP, BRASIL \\ ${ }^{3}$ InStituto de Governo Aberto (IGA), SÃo PAUlo - SP, BRASIL
}

\begin{abstract}
Resumo
O Brasil tem sido um importante locus de implementação de práticas participativas após sua democratização. Em 2011, ao lado de outros sete governos fundadores, o Brasil endossou a Open Government Partnership (OGP) e anunciou os planos para promover maior transparência nas práticas governamentais. O país passou a fazer parte de uma iniciativa multilateral que hoje reúne mais de 70 países. A partir de sua difusão internacional, essa iniciativa foi incorporada pela cidade de São Paulo, que criou o Comitê Intersecretarial de Governo Aberto em 2014. Descrevemos a incorporação do OGP a partir de seu processo de difusão e discutimos os desafios de difusão e institucionalização de uma política global no nível local, ocorrida entre 2013 e 2016. As principais conclusões abordam a importância da institucionalização das práticas políticas além da difusão de políticas; a importância da análise microinstitucional e do trabalho institucional na teoria organizacional para compreender a importância dos principais agentes no processo de implementação; e a influência da arquitetura institucional na implementação do OGP.
\end{abstract}

Palavras-chave: Governo aberto. Difusão. Institucionalização de políticas públicas.

\section{Open Government Partnership in São Paulo City and the São Paulo Aberta program: challenges in the diffusion and institutionalization of a global policy}

\begin{abstract}
Brasil ha sido un lugar importante para implementar prácticas participativas después de su democratización. En 2011, junto con otros siete gobiernos fundadores, Brasil respaldó la Alianza para el de Gobierno Abierto (OGP) y anunció los planes del país para promover una mayor transparencia en las prácticas gubernamentales. El país se convirtió en parte de una iniciativa multilateral que hoy reúne a más de 70 países. Desde su difusión internacional, esta iniciativa fue incorporada por la ciudad de San Pablo, que creó el Comité Intersecretarial de Gobierno Abierto en 2014. Describimos la incorporación de la OGP y de su proceso de difusión y discutimos los desafíos de difusión e institucionalización de una política global a nivel local, entre 2013 y 2016. Las principales conclusiones abordan la importancia de institucionalizar las prácticas políticas además de la difusión de políticas; la importancia del análisis microinstitucional y del trabajo institucional en la teoría organizacional para comprender la importancia de los actores clave en el proceso de implementación; y la influencia de la arquitectura institucional en la implementación de la OGP.
\end{abstract}

Keywords: Open government. Diffusion. Public policy institutionalization.

Open Government Partnership en la ciudad de São Paulo y el programa São Paulo Abierta: desafíos en la difusión e institucionalización de una política global

\begin{abstract}
Resumen
Brasil ha sido un lugar importante para implementar prácticas participativas después de su democratización. En 2011, junto con otros siete gobiernos fundadores, Brasil respaldó la Alianza para el de Gobierno Abierto (OGP) y anunció los planes del país para promover una mayor transparencia en las prácticas gubernamentales. El país se convirtió en parte de una iniciativa multilateral que hoy reúne a más de 70 países. Desde su difusión internacional, esta iniciativa fue incorporada por la ciudad de San Pablo, que creó el Comité Intersecretarial de Gobierno Abierto en 2014. Describimos la incorporación de la OGP y de su proceso de difusión y discutimos los desafíos de difusión e institucionalización de una política global a nivel local, entre 2013 y 2016. Las principales conclusiones abordan la importancia de institucionalizar las prácticas políticas además de la difusión de políticas; la importancia del análisis microinstitucional y del trabajo institucional en la teoría organizacional para comprender la importancia de los actores clave en el proceso de implementación; y la influencia de la arquitectura institucional en la implementación de la OGP.
\end{abstract}

Palabras clave: Gobierno abierto. Difusión. Institucionalización de políticas públicas. 


\section{INTRODUÇÃO}

As práticas de participação e transparência nas políticas públicas, apesar de estarem na agenda desde o processo de redemocratização do Brasil e, principalmente, a partir da Constituição Federal de 1988, foram fortalecidas no período posterior a 2010. Isso ocorreu, entre outros fatores, devido à a difusão e uso da internet pelos governos como medida tanto da digitalização dos serviços e processos administrativos, quanto das formas de relacionamento e comunicação com a população. Soma-se a isso o intenso processo de descentralização de poder para os municípios, também a partir de 1988, que Ihes garantiu a possibilidade de inovar na condução de suas políticas públicas.

Nessa interface entre participação, transparência, uso de tecnologias e combate à corrupção, surgiu em 2011 a Parceria de Governo Aberto (OGP), uma iniciativa multilateral entre países que buscam (i) assumir a agenda por meio da assinatura da Declaração de Governo Abertoㅜ; (ii) estabelecer compromissos em Planos de Ação e; (iii) estabelecer processos de avaliação independentes.

Em 2014, a cidade de São Paulo criou sua própria iniciativa de governo aberto, tornando-se a única cidade do Brasil a aderir à OGP. São Paulo apresenta-se assim como um caso interessante para compreender a descentralização da agenda de governo aberto, entendida aqui como o processo de internalização da agenda no nível municipal. Portanto, este artigo tem como objetivo descrever a difusão da OGP em São Paulo, apresentar os diferentes momentos de institucionalização da política e discutir os desafios da difusão e institucionalização de uma política global no âmbito local.

A teoria institucionalista pode ser definida por três grandes escolas de pensamento: institucionalismo de escolha racional, institucionalismo histórico e teoria institucional organizacional ou institucionalismo sociológico. Apesar de suas próprias características e diferenças, os diferentes tipos de institucionalismo estão unidos pela convicção comum de que as instituições, os arranjos institucionais e os processos sociais são importantes (Immergut, 2006; Hall \& Taylor, 1996). Para explicar nosso estudo de caso, utilizamos a abordagem da teoria institucional organizacional.

A análise é baseada em dados públicos secundários disponíveis, como legislação e relatórios governamentais, e na experiência pessoal de dois dos autores, que foram membros da burocracia do Município de São Paulo entre 2013 e 2016, que é também o período de análise deste artigo. A análise documental foi realizada de forma sistemática a partir dos documentos gerados, como atas de reuniões, oficinas, planos e leis, que, entre outros, serviram para compreender como o processo foi realizado.

O artigo está organizado da seguinte forma: primeiro, uma introdução sobre a difusão do governo aberto globalmente; a seguir, a descrição da implementação da agenda localmente pela Prefeitura de São Paulo; na terceira seção, apresentamos elementos da Teoria Institucional que contribuem para construir uma linha do tempo desse processo. Concluindo, destacamos os pontos-chave para o desenvolvimento e manutenção da agenda de governo aberto em São Paulo.

\section{A AGENDA GLOBAL DO GOVERNO ABERTO}

Governo aberto, segundo o conceito da OGP, pode ser entendido como o uso das tecnologias de informação e comunicação para prover acesso à informação e espaços de participação aos cidadãos; promover a transparência das ações governamentais; e, consequentemente, prevenir e combater a corrupção, fortalecendo a integridade dos assuntos governamentais.

Na agenda de debate no campo da gestão pública, Ramírez-Alujas (2011) apresenta uma tendência da reforma do Estado para promover mudanças no Estado e em sua relação com a sociedade (Ramírez-Alujas, 2011). De forma complementar, Cruz-Rubio (2015) reforça que o governo aberto é um paradigma que fornece um modelo de democracia agregativa e um governo acessível, transparente e receptivo (Cruz-Rubio, 2015, p. 131).

No entanto, de acordo com Hu e Robinson (2012), a definição de governo aberto não tem mais a definição clara que já possuiu². O simples ato de fornecer informações ao público pode ser considerado governo aberto, mas o tipo de informação e os meios pelos quais ela é fornecida afetam o quão aberto um governo é. Ao analisar a Diretiva de Governo Aberto do presidente Obama,

${ }^{1}$ Recuperado de https://www.opengovpartnership.org/process/joining-ogp/open-government-declaration

${ }^{2}$ Mais informações sobre o conceito de governo aberto podem ser encontradas em: https://forum.etalab.gouv.fr/t/what-is-the-concept-of-open-governmentan-approach-to-its-principles/2590 Verifique também: http://www.gigapp.org/ewp/index.php/GIGAPP-EWP/article/view/43 
a Declaração de Governo Aberto (2011, p. 181), e seu compromisso de fornecer informações de alto valor em formatos que o público possa localizar e compreender facilmente, os autores afirmam que essas políticas "turvaram a distinção entre as tecnologias de dados abertos e as políticas de governo aberto", lembrando que uma pode existir sem a outra. Isso significa que um governo pode ser transparente mesmo sem novas tecnologias, e que também pode fornecer dados abertos sobre "tópicos politicamente neutros" e ainda assim não ser "accountable". Nesse sentido, é importante distinguir entre abertura tecnológica e abertura política.

\begin{abstract}
Além disso, a nova amplitude do rótulo de "governo aberto" cria uma associação cognitiva natural entre a accountability cívica e a internet, o que pode ser o melhor. As políticas de accountability que adotam a internet costumam ser muito mais eficazes do que aquelas que não o fazem. (Pode até fazer sentido dizer que se um governo não é transparente por meio da internet, ele efetivamente não é transparente de forma alguma). Mas essa mudança também pode permitir que os funcionários do governo aplaquem o apetite do público por accountability, fornecendo substitutos menos nutritivos $e$ politicamente de baixo impacto (Hu \& Robinson, 2012, pp. 202-203).
\end{abstract}

Para se tornarem membros da OGP, os países candidatos devem endossar uma Declaração de Governo Aberto de alto nível (Open Government Partnership, 2011), apresentar um plano de ação para o país desenvolvido a partir de procedimentos de consulta pública e se comprometer a relatar de forma independente seu progresso. Levando em consideração a colaboração entre as diversas partes interessadas, a OGP é supervisionada por um comitê diretor que inclui representantes de governos e organizações da sociedade civil.

A Parceria de Governo Aberto foi formalmente iniciada em 20 de setembro de 2011, quando os oito governos fundadores (Brasil, Indonésia, México, Noruega, Filipinas, África do Sul, Reino Unido e Estados Unidos) endossaram a Declaração de Governo Aberto e anunciaram os planos de ação de seus países. Desde 2011, a OGP acolheu a inclusão de governos à Parceria.

No total, 78 países $^{3}$ participantes da OGP e 20 governos subnacionais assumiram mais de 2.500 compromissos para tornar seus governos mais abertos e responsáveis (Open Government Partnership, 2016).

De acordo com a OGP, seu principal objetivo na organização e difusão do governo aberto é colaborar com as transformações em um conjunto abrangente de iniciativas de políticas, estimulando os mais altos níveis de abertura política, de mudanças simples a reformas mais complexas, garantindo que essas mudanças estejam beneficiando os cidadãos dos países membros.

O Brasil teve posição de destaque no desenvolvimento da OGP. Desde o seu lançamento, em setembro de 2011, o país co-presidiu a iniciativa com os Estados Unidos até setembro de 2012. A primeira reunião anual da Parceria com 52 membros foi realizada no Brasil, e o país também fez parte do Subcomitê de Coordenação de Liderança e Governança, que é responsável pela promulgação das normas de governança relacionadas à parceria. De acordo com o discurso da presidente Dilma Rousseff:

Para o Brasil, o governo aberto se baseia em três pilares inseparáveis: transparência que permite accountability; participação social que garante a cidadania; e acompanhamento sistemático dos resultados das políticas públicas que garantem uma gestão de qualidade. Tudo isso por meio de tecnologias que permitem a informação adequada, facilitam o acesso e a gestão e permitem um combate mais eficaz à corrupção (OGP Annual Meeting, 2012).

A Controladoria Geral da União - CGU foi responsável por liderar a inclusão do Brasil na Parceria para Governo Aberto, atuando com o setor público e a sociedade civil, além de elaborar o Plano de Ação do Brasil. O Comitê Interministerial para Governo Aberto (CIGA), instituído por Decreto Presidencial promulgado em 15 de setembro de 2011, é responsável por implementar e revisar todos os Planos de Ação. O CIGA é formado por 18 ministérios do governo federal e é coordenado pela Casa Civil da Presidência da República. Possui ainda um grupo executivo formado por integrantes de sete ministérios e coordenado pela CGU4 .

No âmbito municipal, foi durante a gestão de Fernando Haddad (Haddad era do mesmo partido político da presidente Dilma Rousseff) que a política teve início, com a promulgação do Decreto no 54.794/2014. Esse decreto instituiu o Programa São Paulo Aberta e o Grupo de Trabalho Intersecretarial para Governo Aberto (também com a sigla CIGA), comitê formado por membros de 13 secretarias municipais e da Empresa Pública de Tecnologia da Informação e Comunicação de São Paulo -

\footnotetext{
${ }^{3}$ Para verificar todos os membros atuais da OGP, consulte: https://www.opengovpartnership.org/our-members/
}

${ }^{4}$ O CIGA ainda existe e o decreto no 10.160/2019 institui o Comitê Interministerial de Governo Aberto. 
PRODAM para recomendar legislação, bem como promover iniciativas de governo aberto. São Paulo Aberta foi uma iniciativa de política para promover um governo aberto que se baseou em quatro princípios: tecnologia, participação, transparência e integridade. $\mathrm{O}$ uso da tecnologia visa melhorar a vida dos cidadãos; a participação era vista como um aspecto fundamental da tomada de decisões governamentais; a transparência é fundamental para as ações do governo; e integridade é fundamental para coibir a corrupção (São Paulo Aberta, 2017). De acordo com o Decreto Municipal no 54.794/2014:

Art. 10 Fica instituída no âmbito municipal a São Paulo Aberta, iniciativa de governo aberto, que visa integrar e articular as ações e políticas públicas voltadas para:

I - o aumento da transparência e acesso às informações públicas;

II - o aprimoramento da participação social;

III - o fomento à inovação tecnológica;

IV - o fortalecimento da integridade pública, por meio da prevenção e do combate à corrupção;

$V$ - o aprimoramento da governança pública;

VI - a melhoria da prestação de serviços públicos e da eficiência administrativa.

Curiosamente, embora o programa tenha sido implementado antes que a OGP tivesse desenvolvido uma agenda para os governos locais, ele representou uma adesão a todos os princípios da OGP, conforme descreveremos na seção seguinte.

\section{INSTITUCIONALIZAÇÃO DE GOVERNO ABERTO EM SÃO PAULO: DIFUSÃO NACIONAL E INTERNACIONAL DA AGENDA}

A institucionalização da agenda de governo aberto em São Paulo pode ser entendida por quatro momentos distintos: (1) a formação da agenda política e o reconhecimento do tema; (2) a formulação e implementação de iniciativas de governo aberto; (3) o reconhecimento internacional e o relacionamento com a OGP; e, por fim, (4) a paradiplomacia como estratégia para garantir a continuidade. Nesta seção, fazemos um relato detalhado de cada momento, acompanhando o desenvolvimento da iniciativa.

\section{PRIMEIRO MOMENTO - PRIMEIRA ABORDAGEM DA AGENDA DE GOVERNO ABERTO NA CIDADE DE SÃO PAULO}

Sinais da agenda de governo aberto já podiam ser encontrados nas diretrizes ${ }^{5}$ do governo e nas ações realizadas nos primeiros meses de gestão do prefeito Fernando Haddad (2013-2016). Esses sinais incluíram a criação de departamentos responsáveis por políticas de transparência e integridade e a promoção de estruturas de planejamento participativo. A criação da Controladoria Geral do Município - CGM a nível municipal, com a promulgação da Lei no. 15.764, foi uma medida importante, ao estabelecer áreas dedicadas à corregedoria, promoção da integridade e coordenação da política de transparência. Embora existissem espaços participativos na cidade de São Paulo, como conselhos e audiências públicas, criarem-se novos órgãos participativos, os conselhos municipais participativos, órgãos de fiscalização distrital responsáveis pelo acompanhamento das políticas implementadas pelas 32 subprefeituras regionais. Também foram realizadas inúmeras consultas e audiências públicas, que incluíram a revisão do Plano Diretor da cidade (que somou dez mil contribuições) e o desenvolvimento de uma plataforma online na qual os cidadãos puderam apresentar sugestões para o Plano de Metas, que recebeu um total de 9.400 sugestões de atividades territoriais e mais de 800 mensagens eletrônicas ${ }^{6}$.

\footnotetext{
${ }^{5}$ Plano de governo de Fernando Haddad. 2012. Recuperado de http://divulgacandcontas.tse.jus.br/dados/2012/1699/SP/71072/11/250000050277/ proposta.pdf

6 "Programa de Metas da Cidade de São Paulo 2013-2016". Recuperado de https://www.prefeitura.sp.gov.br/cidade/secretarias/gestao/programa_de_metas/ index.php?p=149999
} 
Essas iniciativas indicaram um movimento em direção a um estilo de governar participativo, transparente e inovador na administração. No entanto, essas ações não foram acompanhadas por esforços de coordenação em torno de uma agenda comum para todas as partes. Na falta de diretrizes gerais para os departamentos, cada um promoveu individualmente suas iniciativas.

Nesse ambiente, o conceito de governo aberto, que aliava os princípios de participação, transparência, inovação e integridade, começou a ganhar força na alta gestão. Isso foi especialmente perceptível durante a redação final do Plano de Metas, e ocorreu por razões internas e externas. Entre os motivos, estão a inclusão de uma diretriz central no Plano de Metas ${ }^{7}$ de gestão descentralizada, participativa e transparente, na qual a Prefeitura se compromete com um conjunto de metas e ações para promover a transparência, a participação e a inovação nos diversos órgãos governamentais; o estabelecimento de uma meta específica (meta 116) para a criação de um Gabinete Digital para promover a participação digital, transparência e inovação; a aproximação entre as áreas técnicas do Gabinete da Prefeitura, da Controladoria Geral da União e da Secretaria de Planejamento, Orçamento e Gestão em reuniões internas, momento em que o termo "governo aberto" apareceu como narrativa contundente das inovações em participação, transparência, integridade e tecnologia que vinham sendo implantadas no início da gestão e que deveriam ser aprofundadas nos anos seguintes; e um processo interno liderado pelo Gabinete do Prefeito para mapear as estruturas participativas da cidade que subsidiariam os debates sobre as novas formas de participação (participação 2.0) e a Política e Sistema Municipal de Participação Social.

Como resultado desses processos, houve um deslocamento da meta 116, que inicialmente visava à criação de um Gabinete Digital, para a implantação da iniciativa São Paulo Aberta. Nesse sentido, a iniciativa foi planejada para coordenar as atividades de vários departamentos nas questões de participação, transparência e inovação que estavam ocorrendo separadamente; promover a adoção de práticas de gestão governamental aberta em todos os departamentos; e - embora não formalmente contribuir para o desenvolvimento da agenda de participação social, uma importante diretriz de todas as administrações do Partido dos Trabalhadores, especialmente com instrumentos de participação digital.

Por fim, vale destacar também alguns marcos importantes para a estruturação da iniciativa São Paulo Aberta. Dentre eles, destacam-se: o desenvolvimento bem-sucedido de iniciativas de difusão pública do conceito de sociedade civil, como o primeiro Encontro Aberta de São Paulo em outubro de 2013; a organização do primeiro Hackathon, que divulgou dados do sistema de transporte público aos cidadãos; a primeira divulgação oficial em São Paulo do termo "governo aberto"; e o projeto Diálogo Aberto de São Paulo, que aconteceu nas "subprefeituras" (órgãos de gestão regional) e contou com a presença de membros dos Conselhos Participativos. Destaca-se também a criação da CIGA, Comissão Intersecretarial de Governo Aberto, por meio da promulgação do Decreto Municipal no 54.794 em 2014.

\section{SEGUNDO MOMENTO - ESTRUTURANDO A AGENDA: PARCERIAS E DESENVOLVIMENTO DE AÇÕES}

Após a estruturação do CIGA e a realização do primeiro evento público de divulgação da agenda de governo aberto, o "Encontro São Paulo Aberta", a iniciativa atingiu um novo patamar.

Dada a complexidade do conceito de governo aberto e as dificuldades de divulgação interna e assimilação de suas propostas, foi necessário dar maior concretude ao tema. Diante desses desafios, a administração definiu como segundo objetivo o estabelecimento de parcerias para estruturar a agenda e deu continuidade a uma série de ações concretas ocorridas ao longo do segundo e terceiro anos de governo.

Nesse sentido, algumas ações foram desenvolvidas para disseminar o conceito e aproximar o governo aberto ao dia a dia de servidores, conselheiros e população em geral. Vários workshops e seminários patrocinados pelo governo foram realizados neste momento, como os apresentados no Quadro 1 abaixo.

Disponível no link anterior. 


\section{Quadro 1}

Workshops e seminários sobre divulgação da OGP em São Paulo

\begin{tabular}{|c|c|}
\hline Nome & \multicolumn{1}{c|}{ Descrição } \\
\hline $\begin{array}{c}\text { Governo Aberto } \\
\text { no Mundo }\end{array}$ & $\begin{array}{l}\text { Workshop voltado para servidores públicos para disseminar o } \\
\text { conceito de práticas de governo aberto na Prefeitura. }\end{array}$ \\
\hline $\begin{array}{c}\text { Ciclo de Treinamento } \\
\text { em Governo Aberto }\end{array}$ & $\begin{array}{l}\text { Conjunto de palestras sobre princípios de governo aberto com } \\
\text { universidades parceiras, como Universidade de São Paulo, } \\
\text { Universidade de Campinas, Universidade Federal do ABCe Fundação } \\
\text { Getúlio Vargas. As aulas foram abertas ao público. }\end{array}$ \\
\hline $\begin{array}{c}\text { Programa Agentes } \\
\text { do Governo Aberto }\end{array}$ & $\begin{array}{l}\text { Programa que concedeu bolsas a representantes da sociedade } \\
\text { civil que apresentaram propostas de cursos e oficinas em temas e } \\
\text { atividades relacionadas aos princípios de governo aberto ao público. }\end{array}$ \\
\hline
\end{tabular}

Fonte: Elaborado pelas autoras.

No primeiro ano, mais de quinze mil pessoas participaram desse programa. Além disso, a São Paulo Aberta criou o Programa Gabinete Aberto, um "talk show" transmitido ao vivo que serviu de ferramenta de responsabilização, ao convidar burocratas de alto e médio escalão a responder a perguntas enviadas pelo público, e para que esses burocratas fossem realizados responsáveis pelas atividades pelas quais eram responsáveis ${ }^{8}$.

Na área da inovação tecnológica, o PRODAM, empresa municipal de TIC, criou o Laboratório de Inovação - LabProdam - cujo objetivo era desenvolver software e ferramentas de base tecnológica para apoiar a gestão e fomentar a participação.

Na dimensão da participação social, a administração instituiu o Comitê Intersecretarial de Articulação Governamental da Política Municipal de Participação Social (instituído pelo Decreto no 55.325 em 2014), a qual cabia a elaboração da política municipal de participação social e também o sistema de participação. Com as ferramentas criadas pelo LabPRODAM em conjunto com outras iniciativas de governo aberto, as secretarias puderam facilmente adotar práticas participativas em suas atividades, especificamente as "Minutas Participativas", para consulta pública de projetos de lei e propostas de regulamentação. Além da esfera digital, a Controladoria-Geral da União intensificou a agenda dos "Cafés Hackers", reuniões informais e colaborativas voltadas para o debate sobre a abertura de dados governamentais e soluções tecnológicas.

Ao longo desse processo, a Secretaria de Relações Internacionais e Federativas (SMRIF), em sua função de coordenadora do CIGA, esteve na vanguarda da maioria dessas ações e, devido às suas próprias competências formais, pôde fazer a ligação com organizações internacionais e governos para divulgar o que foi feito em São Paulo. Nesse sentido, a iniciativa de São Paulo foi apresentada em diversos fóruns estrangeiros e internacionais, em eventos como as missões internacionais de visita à Casa Branca, Madrid e as reuniões da OGP (México em 2015). Isso fez com que, durante o período de implementação, as políticas governamentais de governo aberto pudessem ser apresentadas, desenvolvidas e compartilhadas com outros governos e organismos internacionais, corroborando com a estratégia de difusão que fazia parte da agenda. Além do posicionamento internacional de suas iniciativas, a Secretaria se articulou com outros municípios e governos, inclusive o governo federal, para promover a agenda.

Além de seu papel formal, o Secretariado desempenhou um papel estratégico dentro e fora do governo. Internamente, como um gabinete próximo do prefeito e da posição de seus altos e médios burocratas, conseguiu movimentar-se entre departamentos para promover ações coordenadas, como o "Gabinete Aberto" ou os "Agentes do Governo Aberto ", que envolveu mais três secretarias. No relacionamento com a sociedade civil, a Secretaria conseguiu articular-se com diversos movimentos sociais e organizações da sociedade civil, como o "Fórum de Gestão Compartilhada" para a construção do Plano de Ação de Governo Aberto, apresentado em as seguintes seções.

Independentemente das parcerias desenvolvidas, as ações de governo aberto ainda se localizavam neste espaço. Embora várias iniciativas fossem esforços conjuntos com outros escritórios e atores externos, Governo Aberto como pauta não ultrapassou os limites do SMRIF e CGM, e o assunto foi visto internamente como uma diretriz especialmente para essas secretarias.

\footnotetext{
${ }^{8}$ Ações disponíveis no livro "São Paulo Aberta". Recuperado de https://issuu.com/spaberta/docs/livro_sp_aberta
} 
No entanto, foi nesses anos que o tema governo aberto teve seu destaque - apesar das dificuldades - e ganhou força dentro e fora do governo municipal. Na seção a seguir, descrevemos a próxima fase dos processos iniciados em 2014 e 2015.

\section{TERCEIRO MOMENTO - RECONHECIMENTO INTERNACIONAL DE INICIATIVAS E SELEÇÃO NA OGP}

Em relação às iniciativas de governo aberto, o último ano da gestão de Fernando Haddad (2016) pode ser entendido como de reconhecimento internacional. Como a maioria das iniciativas já havia sido implantada e o tema governo aberto ganhava força dentro e fora do governo ${ }^{9}$, São Paulo passou a ter um papel de destaque nacional e internacional. Neste período, o Programa Agentes de Governo Aberto foi reconhecido como experiência candidata à distinção 10 Observatório Internacional de Democracia Participativa (OIDP) "Boas Práticas de Participação Cidadã". A iniciativa foi apresentada no Fórum OIDP em Barcelona.

Para além deste reconhecimento, o Programa foi selecionado como uma das 10 práticas "Limites do Governo" da Organização para a Cooperação e Desenvolvimento Económico (OCDE) no eixo "Cidadãos como Peritos". Para essa seleção, uma equipe da OCDE visitou a Prefeitura e participou de workshops oferecidos pelos Agentes de Governo Aberto. O caso foi apresentado em um fórum promovido pela OCDE em Dubai no início de 2017 como uma boa prática para quebrar as fronteiras entre o governo e os cidadãos.

Outro caso foi o estudo "Cidadãos Inteligentes, Estado Mais Inteligente", promovido pelo Gov Lab, laboratório de inovação patrocinado pela New York University, que reconheceu a iniciativa Agentes de Governo Aberto como uma boa prática para a capacitação cidadã e fiscalização governamenta $\left.\right|^{10}$. Curiosamente, a coordenadora do estudo no Gov Lab na época era Beth Noveck, que fazia parte da equipe de Barack Obama durante a criação da OGP e outras iniciativas governamentais abertas no governo dos Estados Unidos. Beth Noveck desempenha um papel importante como defensora internacional da agenda de governo aberto e cita regularmente o caso de São Paulo em suas palestras ${ }^{11}$.

Por fim, o principal caso de reconhecimento internacional foi a escolha de São Paulo para fazer parte do programa piloto de subnacionalidades da OGP em 2016. Selecionado por 14 outros governos subnacionais ao redor do mundo, São Paulo foi o representante brasileiro para a promoção da agenda de governo aberto nos anos anteriores à escolha. Em contrapartida, São Paulo elaboraria um Plano de Ação de Governo Aberto, listando as ações a serem implementadas no ano seguinte. No âmbito de uma parceria internacional, a ser descrita na seção seguinte, coube à Prefeitura de São Paulo desenvolver e implementar o plano de ação.

\section{QUARTO MOMENTO - TRANSIÇÃO POLÍTICA E PARADIPLOMACIA}

O quarto momento da iniciativa São Paulo Aberta é o período de transição entre os governos Haddad e Doria e a implantação de dois Planos de Ação firmados com a OGP.

Apesar da transição para cargos de alta gerência, parte do corpo técnico permaneceu nesse período, principalmente servidores efetivos. No entanto, a iniciativa São Paulo Aberta, agora denominada Supervisão para Assuntos de Governo Aberto, teve sua equipe original reduzida a menos da metade do quadro anterior. Isso reflete um enfraquecimento da agenda do governo aberto em termos de suas capacidades administrativas e financeiras para a implementação de políticas, o que pode colocar em risco sua continuidade. Waisbich (2018) corrobora essa visão quanto à falta de vontade política da burocracia de nível

\footnotetext{
${ }^{9}$ Vale ressaltar a quantidade de pessoas envolvidas nessas atividades e sua crescente popularidade ao longo dos anos. Cerca de 100 pessoas participaram do primeiro encontro em 2013 e do "Ciclo de Formação" (ciclo de formação). No 1을 Encontro Brasileiro de Governo Aberto de 2015, estiveram presentes mais de 200 pessoas. Esse número também cresceu no 2o Encontro Brasileiro de Governo Aberto em 2016 para 250 pessoas.

${ }^{10}$ GOVLAB. City of São Paulo: Agents of Open Government. 2016. Recuperado de http://www.thegovlab.org/static/files/smarterstate/saopaulo.pdf

${ }^{11}$ Vídeo "Beth Noveck: Exigindo um governo mais aberto". Recuperado de https://www.youtube.com/watch?v=bLGTrz1Zolk\&t=136s
} 
superior para manter e expandir a implementação de políticas governamentais abertas ${ }^{12}$. Apesar disso, dados abertos e ações relacionadas à transparência foram detalhados no novo Plano de Metas (2017-2020) ${ }^{13}$.

Uma segunda questão que vale a pena ser mencionada foi a nova atribuição de funções da SMRIF ${ }^{14}$. Por ter recebido uma nova diretriz de enfoque apenas na diplomacia, que se relacionava ao fato de seu Secretário Adjunto ser diplomata de carreira, sua nova agenda interna era coerente com a agenda da OGP. Por isso, a paradiplomacia foi fundamental para a continuidade da iniciativa São Paulo Aberta e a implementação do Plano de Ação da OGP, pois conseguiu comprometer a administração com a manutenção de suas políticas, independentemente dos recursos administrativos, financeiros e de pessoal destinados para tal. A paradiplomacia serviu para que a Prefeitura pudesse assumir compromissos internacionais com o Plano de Ação da OGP e dar continuidade às ações.

A Tabela 1, abaixo, enfatiza como o orçamento relacionado às ações governamentais abertas diminuiu drasticamente com as mudanças governamentais. É importante destacar que o orçamento é proposto no ano anterior à sua promulgação, o que significa que Haddad foi responsável pelo aumento orçamentário de 2016 para 2017, assim como Doria foi responsável por sua redução em 2018 e 2019. Bruno Covas foi o responsável para seu aumento em 2020. Além disso, ações de governo aberto poderiam acontecer com orçamentos de outras secretarias, como Cultura, Cidadania e Direitos Humanos. Portanto, há uma zona nebulosa nesta análise, mas é importante considerar a institucionalização pragmática por meio do orçamento.

Tabela 1

Previsão de recursos previstos na Lei Orçamentária Anual (LOA) com ações relacionadas ao Governo Aberto, em reais, 2015-2020

\begin{tabular}{c|c|c|c|c|c|c}
\hline Ano & 2015 & 2016 & 2017 & 2018 & 2019 & 2020 \\
\hline Prefeito & Fernando Haddad & Fernando Haddad & João Doria & João Doria & Bruno Covas & Bruno Covas \\
\hline Previsão (em reais) & $330,000.00$ & $320,000.00$ & $490,000.00$ & $290,000.00$ & $115,000.00$ & $264,000.00$ \\
\hline $\begin{array}{c}\text { Variação em relação } \\
\text { ao ano anterior }\end{array}$ & N/A & $(-) 3 \%$ & $(+) 53 \%$ & $(-) 41 \%$ & $(-) 60 \%$ & $(+) 130 \%$ \\
\hline
\end{tabular}

Fonte: Elaborada pelas autoras baseado em Prefeitura de São Paulo (2020).

O papel desempenhado pelas organizações da sociedade civil, especialmente as que estão associadas ao Fórum de Gestão Compartilhada, uma estrutura de governança participativa composta por membros da sociedade civil e do governo estabelecido em 2016, responsável pelo desenvolvimento e monitoramento do Plano de Ação, também foi essencial. Estas organizações permaneceram ativas e foram estratégicas durante o período de transição de governos, apoiando na tradução da agenda e defendendo a importância de manter a relação com a OGP.

Em 2019, houve mudanças significativas na condução da agenda dentro da Prefeitura de São Paulo. Sob a gestão de Bruno Covas, vice-prefeito de João Doria, a Supervisão para Assuntos de Governo Aberto foi transferida para a Secretaria de Governo Municipal - órgão central de gestão - por meio do Decreto №. 58.596, de 2019. Em meio a estas mudanças, em outubro do mesmo ano, a Supervisão ingressou na Secretaria Executiva de Gestão de Projetos Estratégicos da Secretaria Municipal de Governo (Decreto № 59.000 de 2019), o que reforça a posição estratégica retomada para a agenda do governo aberto.

Um sinal dessa retomada foi a continuidade das ações do governo aberto, tais como: elaboração e implementação do 20 Plano de Ação (2019-2020); as cinco edições do Programa de Agentes do Governo Aberto, iniciado em 2016, assumido como compromisso no Plano de Ação 1 de 2017 e com continuidade nos anos seguintes; co-organização do Encontro Brasileiro de Governo Aberto; e o Diálogo Aberto, uma iniciativa de participação nas subprefeituras.

\footnotetext{
12 "Los retos que emergen frente a un proceso electoral: ¿Qué nos enseña el caso de Sao Paulo, Brasil?" Recuperado de https://www.opengovpartnership.org/ stories/los-retos-que-emergen-frente-un-proceso-electoral-qu-nos-ense-el-caso-de-sao-paulo-brasil

${ }^{13}$ Programa de Metas de São Paulo. Recuperado de http://programademetas.prefeitura.sp.gov.br/

${ }^{14} \mathrm{Na}$ gestão de João Doria, a Secretaria de Relações Internacionais e Federativas (SMIRF) passou por reforma administrativa e passou a se chamar Secretaria de Relações Internacionais (SMRI).
} 


\section{A DIFUSÃO DA POLÍTICA E O PROCESSO DE INSTITUCIONALIZAÇÃO}

A iniciativa São Paulo Aberta e sua relação com a Parceria Governo Aberto é um caso interessante para analisar a relação entre a paradiplomacia e a dinâmica da política local. São Paulo é a maior cidade da América do Sul, com cerca de 11 milhões de habitantes, chegando a 20 milhões, se considerarmos a maior área metropolitana ao redor da cidade. É um importante centro econômico e financeiro e responde por cerca de $11 \%$ do Produto Interno Bruto brasileiro - PIB.

Estudiosos de diferentes áreas começaram recentemente a abordar a questão da difusão de políticas entre países em suas agendas de pesquisa à medida em que o fenômeno se tornou mais frequente. De acordo com Dobbin, Simmons e Garrett (2007), quatro diferentes teorias tentam explicar e descrever os mecanismos de difusão de políticas: a abordagem construtivista, a da coerção, da competição e a teoria do aprendizado.

Ao analisar a São Paulo Aberta, é importante ressaltar que se trata de uma iniciativa política contínua que se modificou devido às mudanças de governo (Fernando Haddad [2013-2016], João Doria [2017-2018] e Bruno Covas [2019-2020]), afetando o processo de difusão e a institucionalização da política de governo aberto, como aqui observado. Entretanto, a análise deste processo contínuo permanece sendo particularmente interessante tanto para o estudo da difusão de políticas como para a ligação entre a literatura sobre difusão de políticas e o processo de institucionalização.

Os teóricos construcionistas sobre difusão de políticas utilizam as lentes da construção social baseadas no trabalho de teóricos como Berger e Luckmann (1985), e Meyer e Rowan (1977), entre outros. Sobre a questão das escolhas políticas, Dobbin et al. (2007, p. 451) afirmam que "tanto fins legítimos quanto meios apropriados são construções sociais compartilhadas que variam de um período para o outro", e o mesmo ocorre com as convenções entre os estados nacionais: "As escolhas políticas são baseadas em modismos, exemplos reverenciados, ou teorias abstratas, em vez de evidências sólidas". A pesquisa demonstra empiricamente como este processo de construção social se desenvolveu no campo da educação e das políticas de direitos humanos. Poderia ser esse também o caso nas políticas de governo aberto? É possível observar uma construção social em ideais de governo aberto?

Por que os países adotam políticas é uma questão que os construtivistas pretendem responder. A aceitação social ocorre quando países que lideram iniciativas servem como exemplos, quando especialistas apoiam novas políticas, recomendam sua adoção e as aprovam sob determinadas circunstâncias (Dobbin et al., 2007). O Brasil seguiu a liderança dos Estados Unidos na OGP e isomorficamente tornou-se co-líder no processo (DiMaggio \& Powell, 1991). Como explicado anteriormente, a OGP ganhou destaque como parte dos esforços do governo Obama para promover accountability no governo.

A coerção também é relevante para a difusão de políticas e acontece quando os governos ou agências multilaterais, por exemplo, garantem a adoção de políticas pela força física (hard power), acordos comerciais que estipulam a implementação de determinadas políticas como um requisito, ou mesmo exercendo o monopólio da informação ou do conhecimento (soft power). Os teóricos da competição acreditam que a difusão da política ocorre quando "os países competem pelos mercados de capital e exportação". Os governos têm pouca escolha senão de optar por políticas favoráveis ao mercado para atrair investimentos globais e manter as exportações competitivas" (p. 457). Por fim, a última estrutura teórica para analisar a difusão de políticas, o aprendizado, "ocorre quando novas evidências mudam nossas crenças" (p. 460), apontado que transformações nas políticas ocorrem quando as ideias e crenças mudam.

No caso de São Paulo Aberta, não focamos na questão da difusão dos ideais do governo aberto por meio da OGP, mas sim no enfraquecimento ou mesmo descontinuidade de uma política importante dentro de um estado democrático. Abordamos estas preocupações nas seções seguintes, discutindo práticas participativas e institucionalização. Este artigo enfatizará a institucionalização na teoria organizacional. Como este campo é amplo e com diferentes correntes de pensamento, vamos nos concentrar no que Grigoletto e Alves (2019) chamam a terceira onda da teoria institucional que se concentra em suas micro fundações. Estes autores contribuem para este campo apresentando uma classificação de três ondas de estudos institucionais, desde seu início com o trabalho de Philip Selznick (1949). 


\section{Uma abordagem institucional da sociedade civil e da participação}

A institucionalização é um processo pelo qual os comportamentos, obrigações ou realidades sociais assumem o status de regra no pensamento social e na ação (Meyer \& Rowan, 1977). É notório que o tempo está diretamente ligado à institucionalização, pois a institucionalização aumenta com a continuidade da transmissão de procedimentos, rotinas, linguagem e treinamento dos atores envolvidos. Quanto maior a institucionalização de um ato, maior capacidade que a instituição tem de mantê-lo sem controle social. Por outro lado, com pouca institucionalização, é necessário o controle direto da sociedade (Zucker, 1977). Em contraste, sob qualquer tentativa de mudança do processo de internalização, uma forte resistência cultural é inevitável. Após o processo de institucionalização, há um processo de legitimação, quando a objetivação de uma ordem institucional é transmitida a uma nova geração. Na legitimação final de uma ordem institucional que conecta eventos passados, presentes e futuros, a linguagem desempenha um papel crucial.

A abordagem institucional das organizações afirma que as instituições são o resultado da atividade humana, mas não necessariamente o produto de um projeto consciente (DiMaggio \& Powell, 1991). A abordagem institucional das organizações coloca ênfase em explicações culturais e cognitivas que são altamente úteis para a compreensão do fenômeno da participação.

Combinando os conceitos institucionais de Greenwood, Oliver, Sahlin e Suddaby (2008) e Scott (2008), afirmamos que as instituições são comportamentos sociais repetitivos vistos como certos, sustentados por elementos reguladores, normativos e culturais cognitivos que dão sentido ao intercâmbio social e permitem a auto-reprodução da ordem social.

No âmbito da abordagem institucional das organizações, as micro fundações do institucionalismo (Powell \& Colyvas, 2008; Powell \& Rerup, 2017) e o trabalho institucional (Hamel, Lawrence \& Tracey, 2017; Lawrence, Sudabby \& Leca, 2011) são de primordial importância para a análise do programa São Paulo Aberta. Estas abordagens destacam a importância do indivíduo (ator) para a análise institucional, revisando a relação entre agência e instituições. Os indivíduos estão envolvidos em processos de criação, manutenção, ruptura e mudança institucional e suas motivações, comportamentos e relacionamentos devem ser observados. Powell e Rerup (2017) "enfatizam que a maioria das micro atividades são cotidianas, destinadas a produzir sensações, alinhar e atrapalhar. Como grupos de pessoas se envolvem em tais ações e resistem também às tentativas dos outros, eles podem muito bem transformar práticas e teorias e alterar identidades pessoais" (p. 312) e afirmam que os estudos sobre micro fundações na última década progrediram significativamente desenvolvendo argumentos teóricos sobre como os eventos de nível macro são afetados pelas atividades de nível micro. Estes indivíduos mantêm e transformam práticas diárias nas quais interesses, valores e paixões se sobrepõem. Neste tipo de análise, é dada ênfase especial à linguagem, vocabulário e arquivos de uma organização que proporcionam uma "conversa longitudinal" sobre como suas atividades são compreendidas.

\section{As micro fundações do institucionalismo}

Como um fenômeno novo, é importante analisar São Paulo Aberta através da lente do que Powell e Colyvas (2008) e Powell e Rerup (2017) chamam de "micro fundações do institucionalismo" e Lawrence et al. (2011) e Hampel, Lawrence e Tracey (2017) chamam de "trabalho institucional". Os autores enfatizam a necessidade de desenvolver biografias institucionais; ou seja, a análise da relação entre indivíduos e instituições específicas e o papel de indivíduos e grupos na criação, formação e ruptura de instituições. Isto significa tentar responder a três perguntas: o quê, quem e como os atores fazem o trabalho institucional.

Hwang e Colyvas (2011) apontam que é possível desenvolver uma microanálise de institucionalização que leva em conta como as instituições são formadas por indivíduos em situações concretas do cotidiano, e como elas são subsequentemente sustentadas, alteradas ou extintas. Esta microanálise serve como um subsídio para análise de macro eventos e relações. É essencial ter uma compreensão mais rica de como os indivíduos se situam dentro das relações sociais e interpretar esse contexto; ou seja, como esses indivíduos mantêm e transformam as forças institucionais que orientam as práticas cotidianas, levando em consideração os interesses e paixões envolvidos no comportamento humano.

Para os autores, as transformações institucionais tendem a ser sutis e requerem um certo período de tempo ao invés de acontecerem de forma abrupta. A maioria dos micromotivos são mundanos e estão sendo interpretados e moldados por atores institucionais, transformando lógicas e identidades. Assim, os autores enfatizam que a análise institucional deve focar mais nos eventos da vida cotidiana do que àqueles considerados específicos e importantes; aos membros menos poderosos das organizações, não apenas seus líderes; e aos aspectos culturais e cognitivos, e não apenas aos políticos. Neste contexto, uma atenção especial aos rituais de interação, ao papel mediador da linguagem e outras categorias servirá para esclarecer como as rotinas e regras organizacionais são desenvolvidas, se institucionalizam e são posteriormente abandonadas. 
Em termos de métodos de pesquisa, a fim de entender como os micro impactos afetam o surgimento e a continuidade das instituições, deve-se dar atenção à linguagem e ao vocabulário, como estes são:

\begin{abstract}
[...] os protocolos que as pessoas utilizam para dialogar e alcançar a compreensão mútua e a consciência intersubjetiva. O próximo passo é ver quais aspectos da linguagem se codificam em medidas formais de desempenho e realização. Essas definições construídas tornam-se métricas pelas quais as pessoas se avaliam umas às outras. medida que esses cálculos de desempenho ou atividade ocorrem, eles se tornam retificados, ou seja, recebidos e aceitos como normais por seus participantes e adotados e imitados por outros que não faziam parte de sua criação inicial. Desta forma, as medidas locais tornam-se "naturais". Uma vez naturais, tornam-se públicas, redefinem e reinterpretam a história, evoluem em modelos aos quais outros aspiram e são reconhecidos como guias de realização (Powell \& Colyvas, 2008, p. 292, Tradução nossa).
\end{abstract}

\title{
Processo de institucionalização
}

Para DiMaggio e Powell (1991), na tradição sociológica, a institucionalização é um processo onde certas relações e ações sociais são tomadas como certas. O conceito de institucionalização e institucionalizado foi definido por Meyer e Rowan no trabalho de 1977, como mostrado por Greenwood et al. (2008):

A institucionalização é o processo pelo qual "processos sociais, obrigações ou realidades passam a assumir uma regra como status no pensamento e ação social" (Meyer \& Rowan, 1977, p. 341). Algo é "institucionalizado" quando se tem esse status de regra. Em um famoso giro de frase, Zucker concluiu que a institucionalização significa que "alternativas podem ser literalmente impensáveis" (1983, p.5). Tolbert e Zucker (1983) sugeriram três indicadores de práticas institucionalizadas: elas são amplamente seguidas, sem debate, e exibem permanência (Greenwood et al., 2008, p. 5, Tradução nossa).

Meyer e Rowan (1977) enfatizam como a incorporação de procedimentos e estruturas do ambiente institucional dá legitimidade à organização, e Di Maggio e Powell (1983) acrescentam que uma vez institucionalizado um certo fato social, modelos de ação que criam respostas unificadas para incertezas geram o isomorfismo institucional; ou seja, a adoção das mesmas práticas por várias organizações que buscam aumentar sua legitimidade, uma vez que que as organizações consideradas legítimas têm suas chances de sobrevivência aumentadas.

O processo de continuidade, manutenção da transmissão de ações, hábitos e procedimentos também aumenta a institucionalização: "quanto mais se conhece a história do processo de transmissão, maior é o grau de continuidade que os atores assumem" (Zucker, 1991, p. 87). Além disso, considerando a resistência à mudança na análise da persistência cultural, o autor afirma que atos fortemente institucionalizados resistirão às tentativas de mudança feitas por influência pessoal.

Lawrence, Winn e Jennings (2001) propõem uma análise que enfatiza a dinâmica temporal e os mecanismos do poder por meio da sistematização dos tempos e dos processos de institucionalização. Eles afirmam que o passo e a estabilidade, duas dimensões temporais do processo de institucionalização, dependem de quatro mecanismos mobilizados pelos agentes para apoiar o processo de institucionalização: influência, força, disciplina e dominação. Sua contribuição pode ser resumida da seguinte forma: apresentando uma compreensão da relação entre a etapa do processo de institucionalização e a estabilidade das instituições, enfatizando o papel do tempo na teoria institucional; criando uma nova tipologia para os mecanismos que sustentam o desenvolvimento e manutenção das instituições; criticando o modelo tradicional de institucionalização vigente; e propondo novas curvas de institucionalização. Em uma curva tradicional de institucionalização há uma fase inicial de aceitação, onde a inovação é primeiramente reconhecida e acolhida por poucos atores, depois amplamente difundida e aceita dentro do campo, e finalmente esta fase é seguida por saturação e completa legitimação. Finalmente, ocorre a desinstitucionalização, um conceito que não é abordado neste estudo.

Ao apresentar quatro mecanismos que influenciam o processo de institucionalização, os autores demonstram que existem variáveis temporais que moldam os diferentes processos possíveis. A primeira variável temporal considera que o grau de difusão de uma regra, prática ou tecnologia dentro de um campo organizacional pode variar muito (certas inovações espalham-se rapidamente, outras lentamente), e isto define o passo da institucionalização. A segunda variável temporal diz respeito ao momento em que uma instituição atingiu o estágio de legitimação e suas práticas são amplamente disseminadas para todos os indivíduos. Ela diz respeito à estabilidade dessa instituição; ou seja, quão estável, permanente e influente a instituição será, 
quer tenha sido institucionalizada rápida ou gradualmente. Em relação aos mecanismos de poder, a influência é uma forma central de poder nas organizações, mas os processos de institucionalização também são influenciados por mecanismos de força, disciplina e dominação que, associados a formas episódicas ou sistêmicas de poder, afetarão certas características relacionadas aos processos de institucionalização. As formas sistêmicas de poder são mais propensas a proporcionar instituições estáveis e de longa duração do que as formas episódicas de poder. No caso de influência e disciplina, o alvo do poder de ambos tem capacidade de agência, ou seja, é capaz de escolher. Estes mecanismos de poder têm influência sobre a questão temporal que envolve o processo de institucionalização.

\section{SÃO PAULO ABERTA: PASSADO E PRESENTE}

Como mencionado na primeira seção, a administração de Fernando Haddad criou a iniciativa São Paulo Aberta e o CIGA para recomendar a regulamentação e promover iniciativas de governo aberto em todos os departamentos do governo, visando aumentar a transparência e o grau de acesso à informação pública; promover a inovação tecnológica; combater a corrupção; aumentar a governança pública; e melhorar a prestação de serviços públicos, a eficiência administrativa e a participação social.

Este movimento de internacionalização por parte do governo municipal de São Paulo expressa uma tendência atual nos governos locais, como declarado por Stern and Friendly (2017). A internacionalização e as redes são motivadas por "fatores impulsionadores, tais como problemas e pressões locais; 2) fatores impulsionadores, tais como oportunidades e incentivos (Marks, Nielsen, Ray \& Salk, 1994); e 3) fatores facilitadores, tais como recursos pessoais, estilo e cultura política e características institucionais (Baldershein, Buček \& Swianiewicz, 1999; Stren \& Friendly, 2017, p. 11).

A iniciativa foi conduzida pela Secretaria de Relações Internacionais de São Paulo e foi concebida como a primeira experiência municipal da OGP no Brasil. Por essa razão, os membros da Secretaria participaram de várias reuniões com a Controladoria Geral da União (CGU), bem como em missões internacionais. No entanto, diferente dos procedimentos regulares que os países buscam se juntar aos países da OGP, São Paulo participou de um processo competitivo de seleção, tendo que cumprir uma série de requisitos, e foi aceito na OGP junto com 14 outros órgãos governamentais locais (Candido, 2017). A São Paulo Aberta já estava implementando uma agenda de governo aberto em convergência com os princípios da OGP, e isto contribuiu para a aceitação de São Paulo na parceria. O prefeito Fernando Haddad, em uma carta oficial à OGP, disse:

\section{A Prefeitura concentrou seus esforços na estruturação de iniciativas que pudessem dar forma concreta à agenda de governo aberto nos municípios e, desta forma, estabelecer uma conexão clara e direta entre os conceitos que forjam esta agenda internacional com as necessidades locais dos cidadãos de uma cidade global como São Paulo. Desta forma, elaboramos, implementamos, monitoramos e avaliamos um conjunto de ações e programas diretamente ligados a cada um dos quatro eixos do Governo Aberto (Haddad, 2016).}

Em 2017, um novo governo foi eleito em São Paulo. João Dória, um recém-chegado do Partido da Social Democracia Brasileira PSDB, venceu as eleições no primeiro turno com uma campanha voltada para uma administração melhor dentro de uma narrativa em que ele, um homem de negócios não político, poderia cumprir. Neste sentido, os termos eficiência, eficácia e efetividade marcariam sua administração, o que também combateria a corrupção. Devido às reduções no orçamento, causadas pela crise econômica e fiscal que o Brasil enfrentava, juntamente com a reorganização da agenda municipal, os funcionários de São Paulo Aberta foram, em sua maioria, demitidos. A equipe foi reduzida de vinte para quatro pessoas, mas a iniciativa foi mantida dentro das atribuições da Secretaria de Relações Internacionais. A internacionalização ainda era uma prioridade do governo de Dória, mas estava voltada para o desenvolvimento de Parcerias Público-Privadas. Embora a cidade de São Paulo fosse membro da OGP, a agenda de governo não estava como prioritária, pois a realocação da Controladoria Geral de São Paulo sob a supervisão da Secretaria de Justiça foi realizada por meio de uma reforma administrativa que reduziu a sua capacidade de supervisão.

João Dória deixou a Prefeitura para concorrer a governador do Estado de São Paulo, ganhando esta eleição em 2017. Em seu lugar, seu vice, Bruno Covas, assumiu parte das ações de governo aberto, sob novas perspectivas e com mudanças em seu formato, como ressaltado anteriormente neste texto. Embora as ações de governo aberto tenham sidas parcialmente 
enfraquecidas no governo Doria, não é possível afirmar de que modo podem ressurgir, ainda que sob um novo foco, no governo Covas. Talvez aqui esteja presente a forma mais interessante de analisar a institucionalização da agenda aberta do governo em São Paulo: sua reconfiguração e permanência mesmo com a eleição de um projeto político que não priorizava esta agenda. Entretanto, as mudanças dos prefeitos e servidores públicos responsáveis pela agenda de governo aberto afetaram diretamente a implementação da política e sua institucionalização porque as pessoas são importantes e responsáveis diariamente pelas atividades. O processo de continuidade, a manutenção da transmissão de ações, hábitos e procedimentos são essenciais para aumentar a institucionalização.

\section{CONSIDERAÇÕES FINAIS}

Após analisar os desafios na difusão e institucionalização da OGP em São Paulo, este artigo enfatiza três pontos. Primeiro, a importância da institucionalização das práticas políticas além da difusão de políticas. Isso significa que a difusão de políticas tem limitações se essas políticas não forem institucionalizadas de fato. Segundo, a importância da análise micro institucional e do trabalho institucional para compreender a importância dos agentes-chave na implementação de uma política. Quando tais agentes se tornam ausentes, os projetos podem ser desviados das prioridades ou até mesmo ser descontinuados. Se as instituições são importantes, as pessoas também são importantes. As pessoas estratégicas em lugares estratégicos fazem a diferença. Em terceiro lugar, a influência da arquitetura institucional da implementação da OGP. A decisão de sediar esta política sob a SMRIF, a Secretaria de Relações Internacionais na administração de Haddad, está relacionada ao pessoal que esteve envolvido no processo e que foi um forte defensor da agenda aberta do governo. Quando este pessoal for substituído, diferentes estruturas de governança poderão se adequar melhor à política, como é possível observar na administração de Bruno Covas. Como o governo aberto deveria ser uma prática abrangente em todo o governo, a coordenação das práticas OGP no município deve ser melhor realizada pelo Secretário de Governo, que tem o papel de estabelecer a estrutura de governança e o relacionamento entre as diferentes secretarias dentro da administração. Finalmente, esta pesquisa se beneficiaria muito da perspectiva de descontinuidade das políticas e de como as mudanças no governo afetam a difusão e a institucionalização das políticas. Além disso, novas pesquisas sobre a transformação da agenda sob as administrações Doria e Covas podem apoiar a compreensão de fenômenos posteriores. 


\section{REFERÊNCIAS}

Baldersheim, H., Buček, J., \& Swianiewicz, P. (2002). Mayors Learning across Borders: The International Networks of Municipalities in East-Central Europe. Regional \& Federal Studies, 12(1), 126-137.

Berger, P., \& Luckmann, T. (1985). A construção social da realidade. Petrópolis, RJ: Vozes.

Cândido, C. T. (2017). São Paulo Aberta: Uma análise do programa de Governo Aberto do município de São Paulo. In Anais do 25 Congresso de Iniciação Científica da UNIFESP, São Paulo, SP.

Cruz-Rubio, C. N. (2015). O que é (e o que não é) governo aberto? Uma discussão conceitual. Rev. Temas de Administração Pública, 10(1), 129-148. Recuperado de https://periodicos.fclar.unesp.br/ temasadm/article/viewFile/8583/6471

DiMaggio, P. J., \& Powell, W. W. (1983). The iron cage revisited: institutional isomorphism and collective rationality in organizational fields. American Sociological Review, 48(2), 147-160.

DiMaggio, P. J., \& Powell, W. W. (1991). Introduction. In P. J. DiMaggio, \& W. W. Powell (Eds.), The new institutionalism in organizational analysis (pp. 1-38). Chicago, IL: The University of Chicago Press.

Dobbin, F., Simmons, B., \& Garrett, G. (2007). The Global Diffusion of Public Policies: Social Construction, Coercion, Competition, or Learning? Annual Review of Sociology, 33, 449-472.

Greenwood, R., Oliver, C., Sahlin, K., \& Suddaby, R. (2008). Introduction. In R. Greenwood, C. Oliver, K. Sahlin, \& R. Suddaby (Eds.), The Sage handbook of organizational institutionalism (pp. 1-46). London, UK: Sage Publications.

Grigoletto, F., \& Alves, M. A. (2019). Leitura do institucionalismo organizacional a partir da teoria do organizar de Karl Weick. Cadernos EBAPE.BR, 17(2), 247-262.

Haddad, F. (2016). Ofício enviado a Senhora Kitty von Bertele, do Comitê Diretor da Open Government Partnership (OGP) - Parceria para Governo Aberto. São Paulo, SP: Prefeitura de São Paulo.

Hall, P. A., \& Taylor, R. C. R. (1996). Political science and the three new institutionalisms. Political Studies, 44(5), 936-957.

Hampel, C. E., Lawrence, T. B., \& Tracey, P. (2017). Institutional Work: Taking Stock and Making it Matter. In R. Greenwood, C. Oliver, K. Sahlin, \& R. Suddaby (Eds.), The Sage Handbook of Organizational Institutionalism (pp. 558-590). London, UK: Sage.

Hu, H., \& Robinson, D. G. (2012). The New Ambiguity of "Open Government". UCLA Law Review Discourse, 59, 178-208.

Hwang, H., \& Colyvas, J. A. (2011). Problematizing actors and institutions in institutional work. Journal of Management Inquiry, 20(1), 62-66.

Immergut, E. (2006). O núcleo teórico do novo institucionalismo. In E. Saravia, \& E. Ferrarezi (Eds.), Políticas públicas: coletânea (Vol. 1). Brasília, DF: ENAP.

Lawrence, T., Sudabby, R., \& Leca, B. (2011). Institutional work: refocusing institutional studies of organizations. Journal of Management Inquiry, 20(1), 52-58.

Lawrence, T. B., Winn, M. I., \& Jennings, P. D. (2001). The temporal dynamics of institutionalization. Academy of Management Review, 26(4), 624-644.
Marks, G., Nielsen, F., Ray, L., \& Salk, J. E. (1994). Competencies, Cracks, and Conflicts: Regional Mobilization in the European Union. Comparative Political Studies, 29(2), 164-192.

Meyer, J. W., \& Rowan, B. (1977). Institutionalized organization: formal structure as myth and ceremony. American Journal of Sociology, 83(2), 440-463.

Open Government Partnership. (2001). From commitment to action. Recuperado de https://www.opengovpartnership.org/wp-content/ uploads/2001/01/OGP_actionplan_guide\%20FINAL.pdf

Open Government Partnership. (2011, September). Open government declaration. Recuperado de https://www.opengovpartnership.org/ process/joining-ogp/open-government-declaration/

Open Government Partnership. (2016). Subnational Government Pilot Program. Recuperado de https://www.opengovpartnership. org/how-it-works/subnational-government-pilot-program

Open Government Partnership. (2018). São Paulo, Brazil - OGP Subnational Pioneers. Recuperado de https://www.opengovpartnership. org/how-it-works/subnational-government-pilot-program

Open Government Partnership. (2020a). Subnational São Paulo Plan. Recuperado de http://www.opengovpartnership.org/ subnational-saopaulo-plan

Open Government Partnership. (2020b). The Basic Engagement. Recuperado de https://www.opengovpartnership.org/how-it-works/ civil-society-engagement/engaging-civil-society-why-and-how

Open Government Partnership. (2020c). What is the Open Government Partnership? Recuperado de http://www.ogpireland. ie/what-does-open-government-mean/

Powell, W. W., \& Colyvas, J. A. (2008). Microfoundations of institutional theory. In R. Greenwood, C. Oliver, K. Sahlin, \& R. Suddaby (Eds.), The Sage Handbook of Organizational Institutionalism (pp. 276-298). London, UK: Sage.

Powell, W. W., \& Rerup, C. (2017). Opening the Black Box: The Microfoundations of Institutions. In R. Greenwood, C. Oliver, K. Sahlin, \& R. Suddaby (Eds.), The Sage Handbook of Organizational Institutionalism (pp. 311-337). London, UK: Sage.

Ramírez-Alujas, A. V. (2011). Gobierno abierto, servicios públicos 2.0 y ciudadanía digital: notas para una nueva agenda de modernización de la gestión pública en Iberoamérica. Madrid, España: Grupo de Investigación en Gobierno, Administración y Políticas Públicas. Recuperado de https://goo.gl/FP4yR6

São Paulo Aberta. (2016). Relações Internacionais e Federativas. Memória da Iniciativa São Paulo Aberta. São Paulo, SP: Prefeitura de São Paulo.

São Paulo Aberta. (2020). Website. Recuperado de http://www. saopauloaberta.com.br

SCOTT, R. (2008). Institutions and organizations: ideas and interests. London, UK: Sage.

Selznick, P. (1949). TVA and the grass roots: a study in the sociology of formal organization (Vol. 43). Berkeley, CA: University of California Press. 
Stren, R., \& Friendly, A. (2017). Mayors in Local Politics: A New Look. In Proceedings of Annual Meeting of the American Political Science Association, San Francisco, CA.

Zucker, L. G. (1977). The role of institutionalism in cultural persistence. American Sociological Review, 42(5), 726-743.

Zucker, L. G. (1987). Institutional theories of organizations. Annual Review of Sociology, 13, 443-464.
Zucker, L. G. (1991). Postscript: Microfoundations of institutional thought. In W. W. Powell, \& P. DiMaggio (Eds.), The new institutionalism in organizational analysis (pp. 103-106). Bingley: Emerald Insight.

Waisbich, L. T. (2018, May 15). Los retos que emergen frente a un proceso electoral: ¿Qué nos enseña el caso de Sao Paulo, Brasil? Open Government Partnership. Recuperado de https://www. opengovpartnership.org/stories/los-retos-que-emergen-frente-aun-proceso-electoral-que-nos-ensena-el-caso-de-sao-paulo-brasil/

Gabriela de Brelàz

ORCID: https://orcid.org/0000-0001-9954-5526

Professora Adjunto da Universidade Federal de São Paulo (UNIFESP) na Escola Paulista de Política, Economia e Negócios (EPPEN).

E-mail: gabriela.brelaz@unifesp.br

\section{Tamara llinsky Crantschaninov} ORCID: https://orcid.org/0000-0003-4841-9452

Professora da Fundação Escola Paulista de Sociologia e Política (FESPSP) do Programa de Pós-Graduação em Ciência Política.

E-mail: tamaracrants@gmail.combr

Laila Bellix

ORCID: https://orcid.org/0000-0003-2345-3558

Co-fundadora do Instituto de Governo Aberto (IGA).E-mail: Ilbellix@gmail.com 